\title{
Synthesis and catalytic activities of porphyrin-based PCP pincer complexes.
}

\section{$\operatorname{AUTHOR}(\mathrm{S}):$}

Fujimoto, Keisuke; Yoneda, Tomoki; Yorimitsu, Hideki; Osuka, Atsuhiro

\section{CITATION:}

Fujimoto, Keisuke ...[et al]. Synthesis and catalytic activities of porphyrin-based PCP pincer complexes.. Angewandte Chemie - International Edition 2013, 53(4): 1127-1130

\section{ISSUE DATE:}

2013-12-11

URL:

http://hdl.handle.net/2433/198445

\section{RIGHT:}

This is the peer reviewed version of the following article: Fujimoto, K., Yoneda, T., Yorimitsu, H. and Osuka, A. (2014), Synthesis and Catalytic Activities of Porphyrin-Based PCP Pincer Complexes. Angew. Chem. Int. Ed., 53: 1127-1130, which has been published in final form at http://dx.doi.org/10.1002/anie.201308551.; この論文は出版社版でありません 。引用の際には出版社版をご確認ご利用ください。;This is not the published version. Please cite only the published version. 


\title{
Synthesis and Genuine Catalytic Activities of Porphyrin- based PCP Pincer Complexes
}

\author{
Keisuke Fujimoto ${ }^{\dagger}$, Tomoki Yoneda ${ }^{\dagger}$, Hideki Yorimitsu ${ }^{\dagger \neq *}$, Atsuhiro Osuka ${ }^{\dagger *}$ \\ ${ }^{\dagger}$ Department of Chemistry, Graduate School of Science, Kyoto University, Sakyo-ku, Kyoto 606-8502, Japan \\ ${ }^{\ddagger}$ ACT-C, JST, Sakyo-ku, Kyoto 6o6-8502, Japan \\ Supporting Information Placeholder
}

\begin{abstract}
Bis(diphenylphosphino)porphyrins undergo peripheral cyclometalation with group to transition metal salts to afford the corresponding porphyrin-based PCP pincer complexes. The porphyrinic plane and the PCP-pincer unit are apparently coplanar with small strain. The genuine catalytic activities of the porphyrin-based pincer complexes at the periphery were investigated in allylation of benzaldehyde with allylstannane and in 1,4-reduction of chalcone to find electronic interplay between the inner metal and the outer metal in catalysis for the first time.
\end{abstract}

Whereas a porphyrin scaffold usually accommodates a metal in its inner cavity to alter its electronic and structural properties, porphyrins bearing a porphyrinic carbon-transition metal $\sigma$ bond on the periphery have been emerging as a new class of porphyrin complexes., ${ }^{1,2,3}$ They are not only structurally novel but also intriguing to investigate electronic interplay between the inner metal and the outer metal. ${ }^{\text {b,e,h, }, 3 a, b}$ In addition, peripherally cyclometalated motifs can serve as linkers in multiporphyrinic assemblies of interest, ${ }^{2 c, h-i, 3 c, e, ~ a n d ~}$ potent chromophores for luminescent and nonlinear optical mateials.

Many conventional porphyrin transition metal complexes show important catalytic activities such as oxygenation. 4 In contrast, the catalytic activities of peripherally metalated porphyrins remain unexplored. $3^{\text {h, }, 5}, 6$ We reported the synthesis of porphyrin-based NCN-pincer palladium complexes $\mathbf{1 M}^{1} \mathbf{P d}$ as the first porphyrin-based pincer complexes ${ }^{3 \mathrm{a}, 7}$ (Chart 1, $\mathrm{Ar}=3,5-t \mathrm{Bu}_{2} \mathrm{C}_{6} \mathrm{H}_{3}$ throughout the manuscript). Intriguingly, their catalytic activities in the Heck reaction depended on the inner metal $\mathbf{M}^{1}$. This activity/inner metal relationship seemed to display the electronic interaction between the inner and outer metals. ${ }^{8}$ However, the mechanism of the Heck reaction catalyzed by a pincer palladium complex has been under intense debate. Many researchers suggested that pincer palladium complexes are most likely to act simply as precursors of highly active palladium(o) colloids at higher temperatures in the Heck reaction. ${ }^{9}$ In other words, $\mathbf{1} \mathbf{M}^{\mathbf{1}} \mathbf{P d}$ would be structurally labile under the reaction conditions to result in irreversible dissociation of the porphyrinic C-Pd $\sigma$ bond. Thus, there are no distinct reports on the genuine catalytic activity of peripherally metalated porphyrins $^{10}$ or on electronic interplay between the inner metal and the outer metal in catalysis. ${ }^{6}$
The structures of the NCN pincer complexes $\mathbf{1} \mathbf{M} \mathbf{P} \mathbf{P d}$ are significantly distorted due to the fused six-membered rings with long $\mathrm{C}-\mathrm{Pd}$ and $\mathrm{N}-\mathrm{Pd}$ bonds as well as the rigid square planar geometry of the palladium center. ${ }^{4 a}$ In pursuit of peripherally metalated porphyrins that are catalytically active without considerable decomposition, we have now developed porphyrin-based PCP-pincer complexes $\mathbf{2}^{\mathbf{1}} \mathbf{M}^{2}$. The PCP pincer unit of $\mathbf{2 M}^{\mathbf{1}} \mathbf{M}^{\mathbf{2}}$ consists of two fused five-membered rings and is hence expected to take a less biased conformation. As phosphines represent the most popular ligands for transition metal catalysts, we envisioned ampler possibilities of $\mathbf{2} \mathbf{M}^{\mathbf{1}} \mathbf{M}^{\mathbf{2}}$ as catalysts but not merely a metal source.

Chart 1. Porphyrin-based pincer complexes.

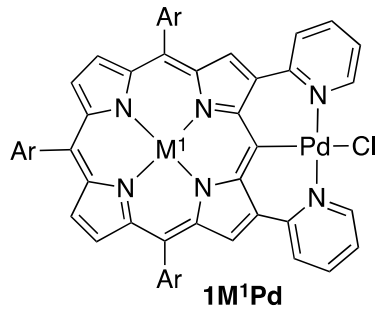

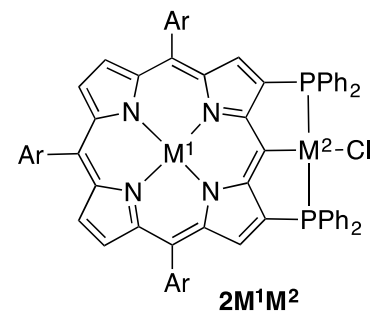

The synthesis of pincer ligand ${ }_{4} \mathbf{M}^{\mathbf{1}}\left(\mathrm{M}^{1}=\mathrm{Ni}\right.$ and $\left.\mathrm{Zn}\right)$ was achieved through palladium-catalyzed phosphination ${ }^{11}$ of porphyrinyl ditriflate ${ }_{3} \mathbf{M}^{\mathbf{1}}$ (Scheme $\mathbf{1}$ ). We were anxious about possible oxidation of the trivalent phosphines to phosphine oxides in air. Indeed, $\mathbf{4} \mathbf{Z n}$ is sensitive to air and was gradually oxidized in solution to lead to a decreased yield of 4Zn. However, ${ }_{4} \mathrm{Ni}$ is stable in air and can be handled without special care, and its structure has been confirmed by Xray diffraction analysis (SI). Porphyrin ${ }_{4} \mathrm{Ni}$ exhibits a Soret band at $427 \mathrm{~nm}$ that is red-shifted by $18 \mathrm{~nm}$ from the parent $\mathrm{Ni}(\mathrm{II})$ porphyrin as an influence of $\beta, \beta$-diphosphination. The following cyclometalation with soluble group 10 metal salts proceeded smoothly in the presence of sodium acetate as a base. Bimetallic pincer complexes $\mathbf{2}^{\mathbf{1}} \mathbf{M}^{\mathbf{2}}$ were isolated as stable solids by recrystallization in good yields. Freebase porphyrin pincer complexes $\mathbf{2} \mathbf{H}_{\mathbf{2}} \mathbf{M}^{\mathbf{2}}$ were obtained by selective removal of the inner zinc of $\mathbf{2} \mathbf{Z n \mathbf { M } ^ { 2 }}$ under acidic conditions, which underscores the robustness of the PCP-pincer structure. 
Scheme 1. Synthesis of porphyrin-based PCP pincer complexes.

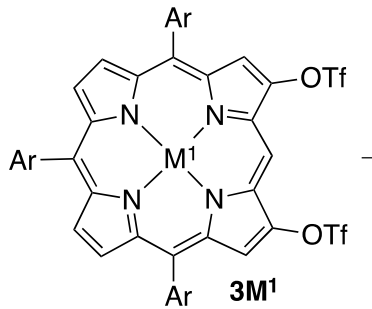
a)

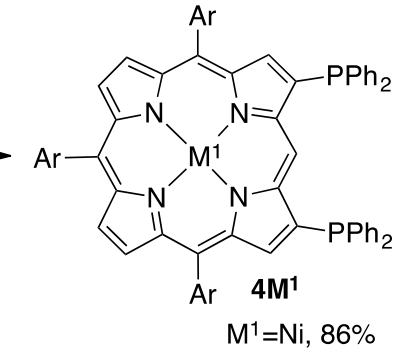
$M^{1}=\mathrm{Zn}, 55 \%$

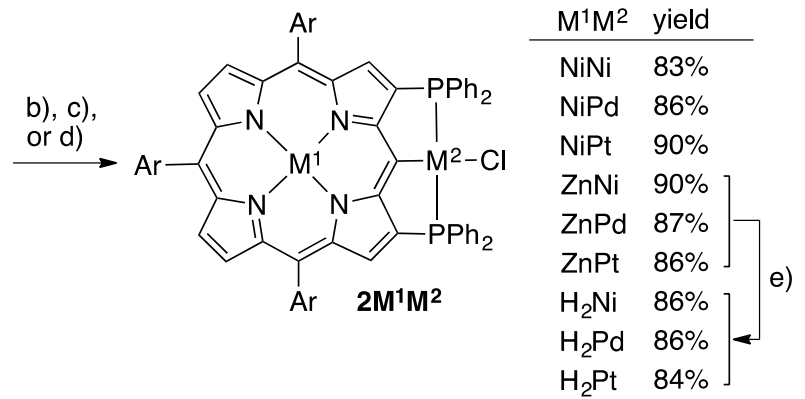

a) 5 equiv. $\mathrm{HPPh}_{2}, 20 \mathrm{~mol} \% \mathrm{Pd}(\mathrm{OAc})_{2}, 20 \mathrm{~mol} \% \mathrm{dppb}, 10$ equiv. $\mathrm{NEt}_{3}, \mathrm{DMF}, 90{ }^{\circ} \mathrm{C}, 12 \mathrm{~h}$; b) 1.1 equiv. $\mathrm{NiCl}_{2}\left(\mathrm{PPh}_{3}\right)_{2}, 1.1$ equiv. $\mathrm{NaOAc}$, toluene, $110{ }^{\circ} \mathrm{C}, \quad 24 \mathrm{~h}$; c) 1.1 equiv. $\mathrm{PdCl}_{2}\left(\mathrm{MeCN}_{2}\right.$, 1.1 equiv. $\mathrm{NaOAc}$, toluene, $80{ }^{\circ} \mathrm{C}, 3 \mathrm{~h}$; d) 1.1 equiv. $\mathrm{K}_{2} \mathrm{PtCl}_{4}, 1.1$ equiv. $\mathrm{NaOAc}$, toluene/DMF, $100{ }^{\circ} \mathrm{C}$, $10 \mathrm{~h}$; e) $\mathrm{TFA} / \mathrm{CH}_{2} \mathrm{Cl}_{2}, 20{ }^{\circ} \mathrm{C}$, $10 \mathrm{~min}$.

The structures of $\mathbf{2 N i M}^{\mathbf{2}}$ were unambiguously determined by X-ray crystallographic analysis (Figure 1 for $2 \mathbf{N i P d}$ and Figure SXX in SI for $\mathbf{2} \mathbf{N i N i}$ and $\mathbf{2 N i P t}$ ). The porphyrinic plane and the PCP-pincer unit are obviously flat together and, especially for $\mathbf{2 N i P d , ~ c o n s t i t u t e ~ a n ~ a l m o s t ~ p e r f e c t ~ p l a n e , ~}$ which is in sharp contrast to the previous NCN-pincer complexes that take highly distorted structures. ${ }^{3 a}$ The porphyrinic $\mathrm{C}-\mathrm{P}$ bonds are directed inward to the outer metal due to strong coordination with $\mathrm{P}_{1}-\mathrm{C}_{1}-\mathrm{C}_{2}$ and $\mathrm{P}_{2}-\mathrm{C}_{5}-\mathrm{C}_{4}$ angles of $114.25^{\circ}$ for both in $2 \mathrm{NiPd}$. The length of the $\mathrm{C}_{3}-\mathrm{Pd}$ bond is 2.014 $\AA$, which is apparently longer than that of our previous NCN-pincer palladium complex ${ }^{3 a}(1.977 \AA)$ and is similar to that of the closely related anthracene-based PCP-pincer palladium complex ${ }^{12}$ (2.010 $\AA$ ).

Electronic perturbations induced by the outer metals were investigated through UV/vis absorption spectroscopy (Figure 2). Compared to parent bidentate ligand ${ }_{4} \mathbf{N i}$, palladium and platinum pincer complexes $\mathbf{2 N i P d}$ and $\mathbf{2 N i P t}$ exhibit similar yet enhanced and red-shifted Soret bands, which would be ascribable to their more rigid conformations. In contrast, homobimetallic nickel complex $\mathbf{2 N i N i}$ displays a broad and largely split Soret band at 397 and $458 \mathrm{~nm}$ and the most redshifted Q-band. Since $\mathbf{2} \mathbf{N i M}^{\mathbf{2}}$ are structurally similar to other porphyrin pincer complexes Figure SXX in SI), the unique absorption of $\mathbf{2} \mathbf{N i N i}$ is attributable to rather strong interaction between the outer nickel $\mathrm{d}$ orbitals and the porphyrinic $\pi$ orbitals.

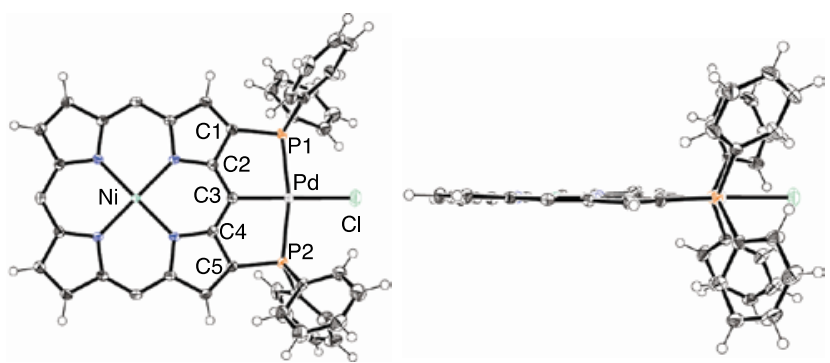

Figure 1. ORTEP Drawings of 2 NiPd. Thermal ellipsoids represent $50 \%$ probability. The meso-aryl groups are omitted for clarity.

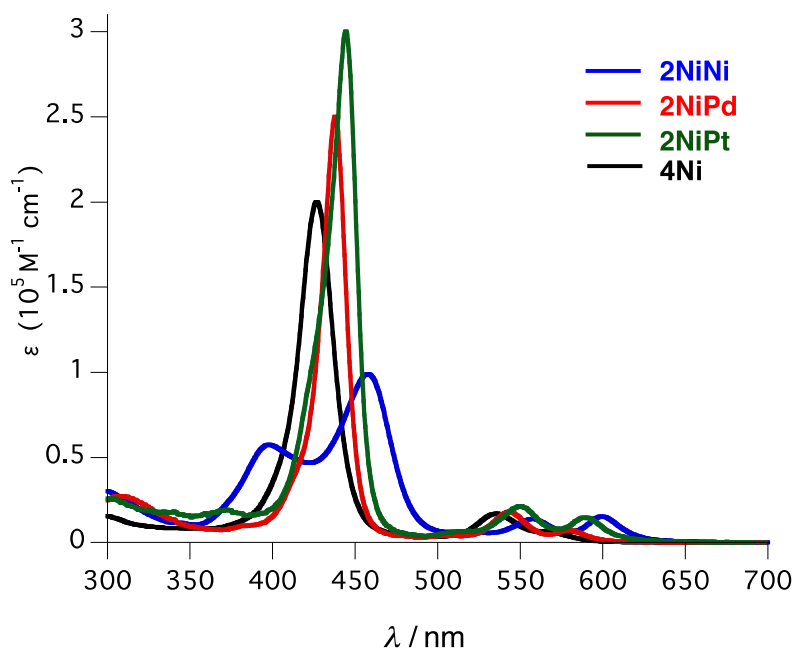

Figure 2. UV/vis absorption spectra of $2 \mathrm{NiNi}$, $2 \mathrm{NiPd}$, ${ }_{2} \mathrm{NiPt}$, and ${ }_{4} \mathrm{Ni}$ in dichloromethane.

Pincer complexes are well known to show a wide spectrum of catalytic activity. 7 Seeking after the catalytic activity of porphyrin-based pincer complexes that sustain their pincer structures during catalytic cycles, we firstly selected catalytic allylation of benzaldehyde with allyltributyltin ${ }^{13}$ as a model reaction. Different from the Heck reaction, the allylation is known to proceed with keeping the valence of the transition metal during the catalytic cycle and without significant decomposition of the catalyst. ${ }^{14}$ Therefore, we considered that the allylation is an ideal reaction to investigate the genuine catalytic activity of porphyrin-based pincer complexes.

The allylation indeed occurred in the presence of $\mathbf{2}^{\mathbf{1}} \mathbf{M}^{\mathbf{2}}$ (Table 1). Additions of $\mathrm{AgPF}_{6}$ are essential to generate catalytically active cationic pincer complexes by removal of the chloride on $\mathrm{M}^{2}$. The allylation that was catalyzed by $2 \mathrm{NiNi}$ or $\mathbf{2 H}_{\mathbf{2}} \mathbf{N i}$ did not go to completion due to decomposition of the catalysts during the reaction. With these two exceptions, the other $\mathbf{2}^{\mathbf{1}} \mathbf{M}^{\mathbf{2}}$ were robust enough to complete the allylation and exhibited very similar catalytic activities regardless of the inner and outer metals. It is worth noting that the pincer catalysts $\mathbf{2} \mathbf{M}^{1} \mathbf{M}^{2}$ could be recovered after the reactions. For example, we recovered $72 \%$ of $\mathbf{2 N i P d}$ after work-up with brine followed by silica gel column purification and recrystallization. The recyclability indicates that the PCP-pincer complexes served as catalysts with their framework intact under the reaction conditions. 
Table 1. Allylation of Benzaldehyde with Allyltin Catalyzed by $\mathbf{2} \mathbf{M}^{\mathbf{1}} \mathbf{M}^{\mathbf{2}}$

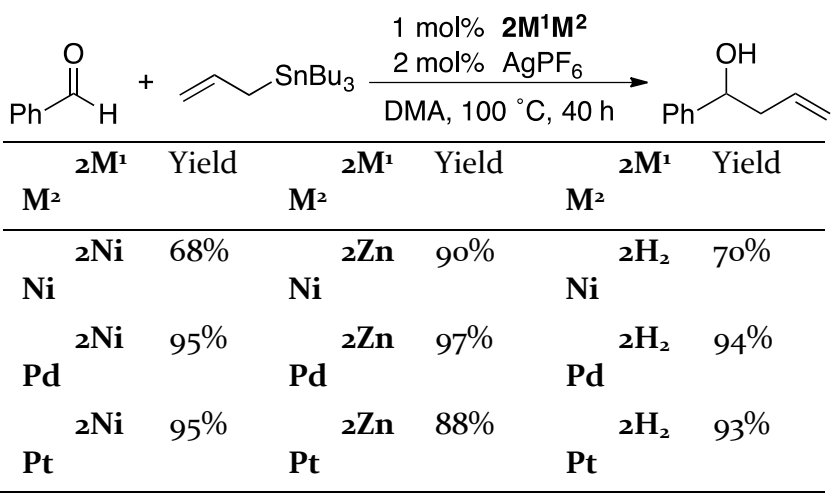

We have also found that peripheral palladium complexes 2M'Pd catalyze 1,4-reduction of chalcone in 1-butanol through transfer hydrogenation. ${ }^{15}$ Interestingly, the catalytic activities have proved to depend on the inner metals. Notably, 2ZnPd showed the highest catalytic activity not only among three $\mathbf{2} \mathbf{M}^{\mathbf{1}} \mathbf{P d}$ complexes (Figure 3 ) but also among all the pincer complexes reported so far. ${ }^{15}$ The reduction did not take place in the presence of $\mathrm{PdCl}_{2}\left(\mathrm{PPh}_{3}\right)_{2}, \mathrm{Pd}_{2}(\mathrm{dba})_{3}$, or $\mathrm{Pd}(\mathrm{OAc})_{2}$ instead of $\mathbf{2} \mathbf{M} \mathbf{P} \mathbf{P d}$, which indicates that not palladium colloids but the pincer complexes do have the catalytic activity.

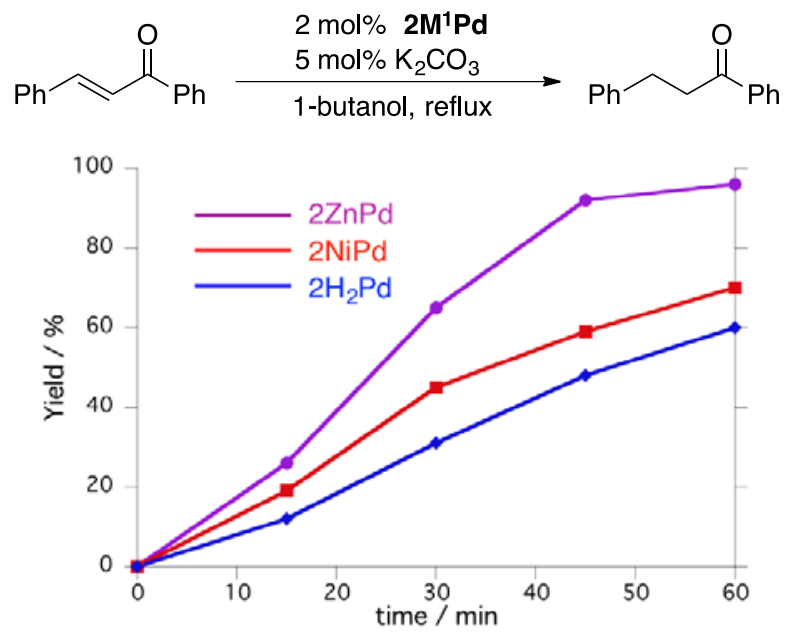

Figure 3. Effect of inner metals on 1,4-reduction catalyzed by $\mathbf{2} \mathbf{M}^{\mathbf{1}} \mathbf{P d}$.

In conclusion, we have synthesized a family of new peripherally metalated porphyrins, porphyrin-based PCP-pincer complexes bearing a meso-carbon-metal $\sigma$ bond. The complexes take rather unbiased and flat geometry. The legitimate catalytic activities of $\mathbf{2} \mathbf{M}^{\mathbf{1}} \mathbf{M}^{\mathbf{2}}$ were investigated in allylation of benzaldehyde with allylstannane and in 1,4-reduction of chalcone. In the latter catalytic reaction, apparent electronic interplay of $\mathbf{2} \mathbf{M}^{\mathbf{1}} \mathbf{P d}$ in catalysis was observed for the first time. Development of new peripherally metalated porphyrin catalysts is under way by taking advantage of the electronic effect of inner metals.

Supporting Information Available
Experimental details and characterization data. This material is available free of charge via the Internet at http://pubs.acs.org.

\section{AUTHOR INFORMATION}

\section{Corresponding Author}

yori@kuchem.kyoto-u.ac.jp, osuka@kuchem.kyoto-u.ac.jp,

Notes

The authors declare no competing financial interest.

\section{ACKNOWLEDGMENT}

This work was supported by Grants-in-Aid from MEXT (Nos.: 24106721 "Reaction Integration" and 25107002 "Science of Atomic Layers") and from JSPS (Nos.: 25220802 (Scientific Research (S)), 24685007 (Young Scientists (A)), 23655037 (Exploratory Research)). T.Y. acknowledges JSPS Fellowship for Young Scientists.

\section{REFERENCES}

(1) Reviews: (a) Shinokubo, H.; Osuka, A. Chem. Commun. 2009, 1011. (b) Hiroto, S.; Yamaguchi, S.; Shinokubo, H.; Osuka, A. J. Synth. Org. Chem. Jpn. 2009, 67, 688. (c) H. Yorimitsu, A. Osuka, Asian J. Org. Chem. 2013, 2, 356. (d) Ren, T. Chem. Rev. 2008, 108, 4185. (e) Suijkerbuijk, B. M. J. M.; Klein Gebbink, R. J. M. Angew. Chem. Int. Ed. 20o8, 47, 7396. (f) Atefi, F.; Arnold, D. P. J. Porphyrins Phthalocyanines 2008, 12, 801. (g) Richeter, S.; Jeandon, C.; Gisselbrecht, J.-P.; Ruppert, R. in Handbook of Porphyrin Science, Vol. 3 (Eds: Kadish, K. M.; Smith, K. M.; Guilard R.), World Scientific Publishing, Singapore, 2010, Chapter 14.

(2) (a) Smith, K. M.; Langry, K. C.; Minnetian, O. M. J. Org. Chem. 1984, 49, 4602. (b) Arnold, D. P.; Sakata, Y.; Sugiura, K.; Worthington, E. I. Chem. Commun. 1998, 2331. (c) Hartnell, R. D.; Arnold, D. P. Organometallics 2004, 23, 391. (d) Hartnell, R. D.; Arnold, D. P. Eur. J. Inorg. Chem. 2004, 1262. (e) Hodgson, M. J.; Healy, P. C.; Williams, M. L.; Arnold, D. P. J. Chem. Soc., Dalton Trans. 2002, 4497. (f) Arnold, D. P.; Healy, P. C.; Hodgson, M. J.; Williams, M. L. J. Organomet. Chem. 20oo, 6o7, 41. (g) Hartnell, R. D.; Yoneda, T.; Mori, H.; Osuka, A.; Arnold, D. P. Chem. Asian J. 2013, Early View, DOI: 10.1002/asia.201300633. (h) Matano, Y.; Matsumoto, K.; Nakao, Y.; Uno, H.; Sakaki, S.; Imahori, H. J. Am. Chem. Soc. 20o8, 130, 4588. (i) Matano, Y.; Matsumoto, K.; Hayashi, H.; Nakao, Y.; Kumpulainen, T.; Chukharev, V.; Tkachenko, N. V.; Lemmetyinen, H.; Shimizu, H.; Kobayashi, N.; Sakamaki, D.; Ito, A.; Tanaka, K.; Imahori, H. J. Am. Chem. Soc. 2012, 134, 1825. (j) Matano, Y.; Matsumoto, K.; Shibano, T.; Imahori, H. J. Porphyrins Phthalocyanines 2011, 15, 1172.

(3) (a) Yamaguchi, S.; Katoh, T.; Shinokubo, H.; Osuka, A. J. Am. Chem. Soc. 2007, 129, 6392. (b) Yamamoto, J.; Shimizu, T.; Yamaguchi, S.; Aratani, N.; Shinokubo, H.; Osuka, A. J. Porphyrins Phthalocyanines 2011, 15, 534. (c) Yamaguchi, S.; Katoh, T.; Shinokubo, H.; Osuka, A. J. Am. Chem. Soc. 2008, 130, 14440. (d) Yamaguchi, S.; Shinokubo, H.; Osuka, A. Inorg. Chem. 20o9, 48, 795. (e) Song, J.; Aratani, N.; Heo, J. H.; Kim, D.; Shinokubo, H.; Osuka, A. J. Am. Chem. Soc. 2010, 132, 11868. (f) Yoshida, K.; Yamaguchi, S.; Osuka, A.; Shinokubo, H. Organometallics 2010, 29, 3997. (g) Yamaguchi, S.; Shinokubo, H.; Osuka, A. J. Am. Chem. Soc. 2010, 132, 9992. (h) Yoshida, K.; Nakashima, T.; Yamaguchi, S.; Osuka, A.; Shinokubo, H. Dalton Trans. 2011, 40, 8773. (i) 
Anabuki, S.; Shinokubo, H.; Aratani, N.; Osuka, A. Angew. Chem., Int. Ed. 2012, 51, 3174.

(4) Reviews: (a) Ruppel, J. V.; Fields, K. B.; Snyder, N. L.; Zhang, X. P. in Handbook of Porphyrin Science, Vol. 10 (Eds: Kadish, K. M.; Smith, K. M.; Guilard R.), World Scientific Publishing, Singapore, 2010, Chapter 43. (b) de Visser, S. P.; Nam, W. in Handbook of Porphyrin Science, Vol. 10 (Eds: Kadish, K. M.; Smith, K. M.; Guilard R.), World Scientific Publishing, Singapore, 2010, Chapter 44. (c) Meunier, B. Chem. Rev. 1992, 92, 1411.

(5) Porphyrins that have a substituent bearing a transition metal-carbon bond, that is, indirectly peripherally metalated porphyrins, are known to show catalytic activities: (a) Suijkerbuijk, B. M. J. M.; Herreras Martinez, S. D.; van Koten, G. Klein Gebbink, R. J. M. Organometallics 2oo8, 27, 534. (b) Suijkerbuijk, B. M. J. M.; Tooke, D. M.; Lutz, M.; Spek, A. L.; Jenneskens, L. W.; van Koten, G. Klein Gebbink, R. J. M. J. Org. Chem. 2010, 75, 1534 .

(6) Richeter nicely demonstrated that N-heterocyclic carbene-fused $\pi$-extended porphyrins can coordinate to generate the corresponding rhodium complexes, the electronic properties of which are modified upon internal protonation or metalation: Lefebvre, J.-F.; Lo, M.; Leclercq, D.; Richeter, S. Chem. Commun. 2011, 47, 2976.

(7) Reviews for pincer complexes: (a) Albrecht, M.; van Koten, G. Angew. Chem., Int. Ed. 2001, 40, 3750. (b) van der Boom, M. E.; Milstein, D. Chem. Rev. 2003, 103, 1759. (c) Singleton, J. T. Tetrahedron 2003, 59, 1837. (d) The Chemistry of Pincer Compounds; Morales-Morales, D., Jensen, C. M., Eds.; Elsevier: Amsterdam, 2007. (e) Selander, N.; Szabó, K. J. Chem. Rev. 2011, 111,
2048. (f) Nishiyama, H. Chem. Soc. Rev. 2007, 36, 1133. (g) van Koten, G. J. Organomet. Chem. 2013, 730, 156.

(8) Matano reported that peripheral palladium complexes of meso-(diphenylphosphino)porphyrins are catalytically active similarly for the Heck reaction although the actual catalytic species has not been characterized. See ref $\mathbf{2 j}$.

(9) (a) Beletskaya, I. P.; Cheprakov, A. V. J. Organomet. Chem. 2004, 689, 4055. (b) Eberhard, M. R. Org. Lett. 2004, 6, 2125. (c) de Vries, J. G. Dalton Trans. 20o6, 421. Also see ref. 7c and 7e.

(10) We reported that 1,4-reduction of ethyl cinnamate with hydrosilane in the presence of a porphyrin-based NCN pincer Ir complex. However, there is no discussion about the stability of the Ir complex during the reaction and about the actual catalytic species. See ref. 3 h.

(11) Gilbertson. S. R.; Starker, G. W. J. Org. Chem. 1996, 61, 2922.

(12) Haenel, M. W.; Jakubik, D.; Krüger, C.; Betz, P. Chem. Ber. 1991, 124, 333.

(13) (a) Solin, N.; Kjellgren, J.; Szabo, K. J. Angew. Chem., Int. Ed. 2003, 42, 3656. (b) Solin, N.; Kjellgren, J.; Szabo, K. J. J. Am. Chem. Soc. 2004, 126, 7026. (c) Yao, Q.; Sheet, M. J. Org. Chem. 2006, 71, 5384 .

(14) Pijnenburg, N. J. M.; Cabon, Y. H. M.; van Koten, G.; Klein Gebbink, R. J. M. Chem. Eur. J. 2013, 19, 4858.

(15) (a) Ding, B.; Zhang, Z.; Liu, Y.; Sugiya, Y.; Imamoto, T.; Zhang, W. Org. Lett. 2013, 15, 3690. (b) Fulmer, G. R.; Herndon, A. N.; Kaminsky, W.; Kemp, R. A.; Goldberg, K. I. J. Am. Chem. Soc. 2011, 133, 17713. 


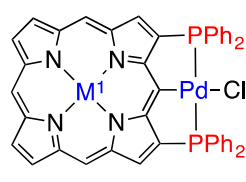

2Mำ $\mathrm{M}^{1}=\mathrm{Zn}, \mathrm{Ni}, \mathrm{H}_{2}$

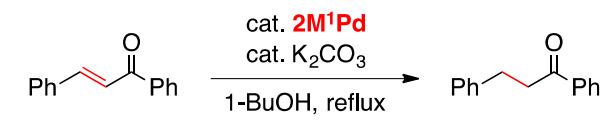
electronic interplay of the inner and outer metals 